\title{
Altered Resting-State Functional Connectivity in the Default Mode Network in Male Juvenile Violent Offenders
}

\author{
Qiaoling Sun ${ }^{1,2} \cdot$ Yingdong Zhang $^{3} \cdot$ Jiansong Zhou ${ }^{1,2} \cdot$ Xiaoping Wang $^{1,2}$
}

Accepted: 7 August 2021 / Published online: 4 September 2021

(c) The Author(s) 2021

\begin{abstract}
Young males are often associated with more violence, leading to some serious negative consequences. However, the physiology and the neuroimaging patterns underlying juvenile violence remain unclear. Of the limited knowledge on juvenile violence, the default mode network has been known to be associated with its pathophysiology. This study aimed to investigate functional connectivity alterations of the default mode network in male juvenile violent offenders. 31 juvenile violent offenders in a high-security facility, who were convicted of aggressive behaviors by court, and 28 normal controls from a middle school were recruited as participants. They underwent a resting-state functional magnetic resonance imaging scan. And independent component analysis approaches were used to analyze their data. Compared to the normal controls, the juvenile violent offenders showed a different default mode network pattern, with the functional connectivity increased in the posterior cingulate, and decreased in the right middle temporal, left angular, right precuneus and right middle frontal cortex. Our findings revealed that the male juvenile violent offenders were associated with abnormal default mode network functional connectivity, which might be a neuroimaging basis for their tendency to violence.
\end{abstract}

Keywords Juvenile violence $\cdot$ Resting-state fMRI $\cdot$ Default mode network $\cdot$ Functional connectivity

\section{Introduction}

In recent years, the number of violent crimes has been increasing worldwide (Krug et al., 2002; Mikton et al., 2016), with juveniles and young adults associated with a higher rate of violent crimes than those in other age groups. According to statistics, they are also responsible for a large number of violent crimes (Piquero et al., 2003). It is estimated that the prevalence of juvenile violence worldwide is as high as $30 \%$, which has posed great impact on themselves and the society (Czabański, 2008). Violence involvement in

Xiaoping Wang

xiaop6@csu.edu.cn

1 Department of Psychiatry, the Second Xiangya Hospital, Central South University, 139 Middle Renmin Road, Changsha 410011, Hunan, China

2 China National Clinical Research Center On Mental Disorders (Xiangya), China National Technology Institute On Mental Disorders, Hunan Key Laboratory of Psychiatry and Mental Health, Changsha 410011, Hunan, China

3 Department of Psychiatry, Hebei Medical University First Affiliated Hospital, Shijiazhuang 050000, Hebei, China the period of adolescence is associated with more frequent and more serious crimes in the offenders' life (McDougall et al., 2015), which may further lead to serious negative consequences in their adulthood, such as impaired social relations, lower level of education and increased rate of victimization (Farrington, 2003). It also causes enormous financial burden (Welsh et al., 2008) due to the direct costs of health care and indemnities, as well as indirect costs incurred from declined productivity, injuries and diseases caused by youth violence. According to the global data released by the World Health Organization, the rates of violent crimes by males are significantly higher than those by females in all age groups, with the crime rate among male adolescents (15-29 years old) being the highest (Krug et al., 2002), suggesting that young males are the main group of violent crimes among all age groups. A better understanding of the biological mechanisms underlying violent behaviors in juveniles, therefore, may bring great benefits to the society through providing basis for the identification, management and prevention of violence.

To date, many studies have been directed towards the neurobiology of violence. However, the physiology and the neuroimaging patterns of violence, especially juvenile 
violence, still remain unclear. According to some studies, biological changes and impairments in some brain regions were related to impulse and violence (Piquero et al., 2003) and might be an important biological factor of violence. In recent years, some neuroscientific studies have found that the brain is more like a huge intricate network and the cognitive, thinking, and controlling functions rely on its comprehensive processing of information (Piquero et al., 2003). As the most important brain network, the default mode network (DMN) is constantly preparing the brain for any upcoming stimulus, thus affecting the perception and response to stimuli (Welsh et al., 2008). Alterations of this network might lead to differences in individual's sensory and cognitive functions, which can further result in different behavioral responses to the same stimulus (Piquero et al., 2003). The DMN is composed of a group of distant brain regions (Welsh et al., 2008), including the posterior cingulate cortex, precuneus, medial prefrontal cortex and lateral/medial temporal lobes, and plays an essential role in emotional processing, monitoring environment changes, self-introspection, maintaining selfawareness, as well as extracting episodic memories (Piquero et al., 2003). This network is also crucial in the integration of information (Welsh et al., 2008) and has significant functional relation with other areas of the brain. A study suggested that abnormal information integration associated with the DMN is an important factor in the cognition dysfunctions in many disorders (Mckinlay et al., 2013; Rosell et al., 2015). An aberrant activity or connectivity within the DMN might also be associated with abnormal internal reactions to external stimuli, affecting various emotional and behavioral processes (Rosell \& Siever, 2015).

Functional magnetic resonance imaging (fMRI) is a useful tool for understanding the neurobiological basis of violence (He, 2014; Meehan \& Bressler, 2012). With good functional and spatial resolution, this technology has enabled us to seek to understand the functional connectivity within brain networks. Many studies that assessed brain networks using fMRI have shown that changed functional connectivity of distant brain regions may lead to tendency of violence (Deco et al., 2011; Fox \& Raichle, 2007). According to recent literature, violent and non-violent individuals exhibit different baseline neurobiological architecture (Boly et al., 2007), which also involved the DMN (Buckner et al., 2008; Laird et al., 2009). However, most relevant studies have focused on adults (Immordino-Yang et al., 2012; Luo et al., 2011). According to a growing amount of neuroscientific evidence, compared with adult brains, developing brains show important differences in functional organization and activities, such as weaker long-distance connections and stronger short-distance connections in children's brains (Jacobs et al., 2013). Therefore, through comparing functional brain activities of DMN in juvenile violent offenders with normal controls, we may find clues for why these offenders are more prone to resort to violence, and improve our understanding of the fundamental brain mechanisms underlying violence.

The objective of the present study is to investigate the DMN of male juvenile violent offenders and normal teenagers and explore the abnormal patterns of the DMN in juvenile violent offenders. Based on previous studies, we hypothesized that compared to normal controls, juvenile violent offenders may have a different DMN activity or connectivity pattern.

\section{Methods}

\section{Participants}

Thirty-one male juvenile violent offenders, who were convicted of aggressive behaviors by court, were recruited from the Hunan Provincial Youth Detention Center in China on the basis of the severity of their index offense as recorded by the police. Specifically, all of their crimes were homicide or assault. Twenty-eight normal controls without any history of violent behaviors were recruited from a middle school in Changsha City. All the participants were between 15 and 18 years of age, right-handed (self-reported), and had no history of neurological impairment. All the interviews were conducted by psychiatrists who were informed about the nature of this study. We used the Chinese version of the Schedule for Affective Disorders and Schizophrenia for School-Age Children Present and Lifetime version (K-SADS-PL) (Pessoa, 2008) to assess the participants' current and lifetime psychiatric problems according to the DSM-IV criteria. The detailed assessment process using K-SADS-PL can be found in our previous study (Zhou et al., 2012).

Information about each participant's criminal history, psychosocial history, use of alcohol or other drugs, family history, and history of psychiatric and other medical treatments was also collected and recorded. Individuals with any current or lifetime schizophrenia and other psychotic disorders, bipolar disorders, major depressive disorder and the history of substance misuse within the past 3 months were excluded. All the participants were assessed using the Barratt Impulsiveness Scale 11(BIS-11), which consists of 30 items about common impulsive or non-impulsive behaviors and involves three factors: (1) attentional impulsiveness, or the lack of focus on a task engaged; (2) motor impulsiveness, or the ability to inhibit proponent responses; (3) nonplanning impulsiveness, or the lack of future planning and forethought (Patton et al., 1995). According to previous data, the score of the scale is correlated with risk behaviors and clinical symptoms (Stanford et al., 2009). 
All the subjects and their legal guardians were fully informed of the procedures and signed the written informed consent form. The study was approved by the Biomedical Ethics Board of the Second Xiangya Hospital of Central South University in China.

\section{MRI Acquisition}

Images were obtained with the use of a Siemens 3 T MRI scanner (Siemens Allegra; the Magnetic Resonance Center of Hunan Provincial People's Hospital, Hunan, China). The following parameters were applied for the functional imaging: repetition time/echo time (TR / TE) $=3000 / 30 \mathrm{~ms}, 36$ slices, $64 \times 64$ matrix, $90^{\circ}$ flip angle, $240 \times 240 \mathrm{~mm}^{2} \mathrm{FOV}$, $3 \mathrm{~mm}$ slice thickness and no gap. A total of 100 volumes were recorded. Participants were required to simply rest motionlessly in the scanner with their eyes closed during the scanning and not to fall asleep or perform any specific cognitive exercise.

\section{Data Preprocessing}

Data preprocessing was conducted in Matlab (R2013b) using the statistical parametric mapping software package (SPM12, http://www.fil.ion.ucl.ac.uk/spm/software/spm12/). The first five time points were removed to only include MR signals in a steady state. The remaining fMRI data underwent the slice timing, before the head motion was corrected by estimating the values of translation $(\mathrm{mm})$ and rotation (degree) for each participant. More than $2 \mathrm{~mm}$ of maximum displacement in $\mathrm{x}, \mathrm{y}$, or $\mathrm{z}$ axes and $2^{\circ}$ of angular motion during the scanning was considered as excessive head movement, and one participant in the offender group was excluded for this reason. The remaining 30 juvenile violent offenders and 28 normal controls were included for further independent component analysis (ICA). The images were normalized to the standard Montreal Neurological Institute (MNI) template, resampled to $3 \times 3 \times 3 \mathrm{~mm}^{3}$, and smoothed with an isotropic Gaussian kernel (full-width at half-maximum $=8 \mathrm{~mm}$ ) to reduce spatial noise.

\section{Group ICA and DMN identification}

Spatial ICA was performed using the Group ICA in the fMRI Toolbox (GIFT) (http://mialab.mrn.org/software/\# gica) to identify independent components (ICs) for all the 58 participants. Dimension estimation on the datasets of the two groups was performed to determine the number of ICs using the minimum description length criterion. 27 ICs were identified and were acquired using the infomax algorithm. Network components were examined visually to eliminate those obvious artifacts. Then the DMN components of the two groups were selected based on the largest spatial correlation with a DMN template offered by GIFT.

\section{Statistical analysis}

Statistical analyses of demographics and clinical data were carried out using the Statistical Package for Social Sciences (SPSS) version 23.0 (SPSS, Chicago, Ill., USA), and the fMRI images were analyzed using the Resting-State fMRI Data Analysis Toolkit (REST) (Wahlund et al., 2009). The normality of continuous data was evaluated using the Kolmogorov- Smirnov one-sample test. Age, education and BIS attentional impulsiveness score did not fit the normal distribution, and these three variables were analyzed with the Mann-Whitney U test. BIS total score and the other two factors was normally distributed, and these variables were analyzed with the two-sample t-test. Chi-squared test or Fisher's Exact Test was used for the analyses of categorical variables. The significance level was set at 0.05 for all the analyses. After the spatial maps of each DMN were extracted from the data of all participants, random-effects analysis using one-sample $t$-tests ( $p<0.05$, with FDR correction) was performed for each group. To explore the DMN differences between the two groups, two-sample $t$-tests was then performed on the individual DMN maps with AlphaSim correction $(p<0.05)$ using the REST software, on basis of the Monte Carlo simulation in AFNI (http://afni.nimh.nih. gov/afni/doc/manual/AlphaSim). A combination threshold of voxels' $p<0.001$ and cluster size $>351 \mathrm{~mm}^{3}$, which corresponded with a corrected $p<0.05$, was considered significant. Age and education level were included as covariates in the statistical analyses of the present functional data. In addition, Spearman's correlation was calculated between variations in DMN z values and BIS-11 scores within the offender group. Correlation analysis was performed using SPSS 23.0, with the significance level set at a significance level of $p=0.05$.

\section{Results}

\section{Demographics and Clinical Characteristics}

The demographic and clinical characteristics of the 30 juvenile violent offenders and 28 normal controls included for analysis of DMN are presented in Tables 1 and 2. According to our analyses, the juvenile violent offenders had a significantly lower education level and family income, a significantly higher rate of smoking, drug and alcohol use, and were approximately one year older than the normal controls. There were also significant differences between groups in BIS-11 total score, scores of all the three BIS-11 factors and the detection rate of conduct disorder. The juvenile violent 
Table 1 Characteristics of the participants

\begin{tabular}{|c|c|c|c|c|}
\hline & $\begin{array}{l}\text { Juvenile violent offenders } \\
(n=30)\end{array}$ & $\begin{array}{l}\text { Normal controls }(n \\
=28)\end{array}$ & Statistical value & $p$ \\
\hline Age (year) & $17.03 \pm 0.72$ & $16.00 \pm 0.38$ & 84.00 & $<0.001$ \\
\hline Education (year) & $7.83 \pm 2.07$ & $10.03 \pm 0.00$ & 101.00 & $<0.001$ \\
\hline Smoking, $n(\%)$ & $29(96.7)$ & $5(17.9)$ & 37.083 & $<0.001$ \\
\hline History of drug use, $n(\%)$ & $15(50.0)$ & $0(0.0)$ & 18.884 & $<0.001$ \\
\hline History of alcohol use, $n(\%)$ & $29(96.7)$ & $21(75.0)$ & 5.718 & 0.017 \\
\hline Family income (monthly), $n(\%)^{\mathrm{a}}$ & & & 22.209 & $<0.001$ \\
\hline$<1000$ & $19(63.3)$ & $3(10.7)$ & & \\
\hline $1000-1999$ & $11(36.7)$ & $15(53.6)$ & & \\
\hline$\geq 2000$ & $0(0.0)$ & $10(35.7)$ & & \\
\hline Parental marital status (divorced), $n(\%)$ & $4(13.3)$ & $2(7.1)$ & 0.598 & 0.439 \\
\hline Main guardian, $n(\%)$ & & & 0.308 & 0.857 \\
\hline Parents & $27(90.0)$ & $24(85.7)$ & & \\
\hline Grandparents & $2(6.7)$ & $3(10.7)$ & & \\
\hline Other & $1(3.3)$ & $1(3.6)$ & & \\
\hline Family type, $n(\%)$ & & & 0.474 & 0.925 \\
\hline Extended family & $4(13.3)$ & $4(14.3)$ & & \\
\hline Core family & $23(76.7)$ & $20(71.4)$ & & \\
\hline Single-parent family & $1(3.3)$ & $2(7.1)$ & & \\
\hline Not living with parents & $2(6.7)$ & $2(7.1)$ & & \\
\hline \multicolumn{5}{|l|}{ Type of crime, $n$} \\
\hline Homicide & 3 & - & & \\
\hline Intentional injury & 14 & - & & \\
\hline Robbing and causing more than minor injuries & 12 & - & & \\
\hline Rape and cause minor injuries & 1 & - & & \\
\hline Duration of penalty (months), median (IQR) & $90(57-123)$ & - & & \\
\hline Time served (months), median (IQR) & $18(12-20)$ & - & & \\
\hline
\end{tabular}

${ }^{a}$ note: Chinese Yuan (CNY), minimum monthly salary (per person); n: number; IQR: interquartile range

Table 2 Descriptive statistics for impulsiveness (BIS-11) and K-SADS-PL

\begin{tabular}{|c|c|c|c|c|}
\hline & $\begin{array}{l}\text { Juvenile violent } \\
\text { offenders }(n=30)\end{array}$ & Normal controls $(n=28)$ & Statistical value & $p$ \\
\hline \multicolumn{5}{|l|}{ BIS } \\
\hline Total score & $72.47 \pm 4.74$ & $64.57 \pm 5.54$ & 5.844 & $<0.001$ \\
\hline Attentional impulsiveness & $19.40 \pm 3.07$ & $22.14 \pm 2.41$ & 185.500 & $<0.001$ \\
\hline Motor impulsiveness & $24.20 \pm 2.98$ & $21.43 \pm 3.34$ & 3.342 & 0.001 \\
\hline Non-planning impulsiveness & $28.87 \pm 3.35$ & $21.00 \pm 2.09$ & 10.804 & $<0.001$ \\
\hline \multicolumn{5}{|c|}{ Diagnosis of any disruptive behavioral disorder, $n$} \\
\hline Attention deficit Hyperactivity disorder & 2 & 0 & 1.933 & 0.492 \\
\hline Oppositional defiance disorder & 7 & 0 & 7.430 & 0.11 \\
\hline Conduct disorder & 24 & 1 & 34.496 & $<0.001$ \\
\hline Previous diagnosis of alcohol abuse, $\mathrm{n}^{\mathrm{b}}$ & 3 & 0 & 2.953 & 0.238 \\
\hline Previous diagnosis of drug abuse, $\mathrm{n}^{\mathrm{b}}$ & 5 & 0 & 5.107 & 0.053 \\
\hline
\end{tabular}

${ }^{\mathrm{b}}$ Note: They had not been off drugs or alcohol for at least ten months 
offenders also had significantly higher scores for the overall BIS-11 scale, motor impulsiveness and non-planning impulsiveness, significantly lower scores in the factor of attentional impulsiveness, compared with the normal controls; they were also associated with higher detection rate in conduct disorder.

\section{Intra-Group ICA Analyses}

The one-sample $t$-tests revealed a typical spatial pattern in the DMN in the two groups (Fig. 1), which included brain regions such as the bilateral medial prefrontal cortex, the posterior cingulate cortex/precuneus, anterior cingulate cortex, bilateral angular gyri and middle temporal gyrus.

\section{Inter-Group ICA Analyses}

The results of two-sample $t$-tests showed significant differences in DMN between the two groups $(p<0.05$, AlphaSim correction). The connectivity differences were found in the posterior cingulate, left angular, right precuneus, right middle frontal and right middle temporal (Fig. 2). The regions displaying DMN connectivity differences, along with the MNI coordinates of the peak foci, were listed in Table 3. Compared with the normal controls, the offenders showed increased functional connectivity in the posterior cingulate, and decreased functional connectivity in the right middle temporal, left angular, right precuneus and right middle frontal.

\section{Correlation Analysis of the Offender Group}

No correlation was found between the BIS-11 total score or scores of three factors and the connectivity in the right middle frontal, right precuneus, left angular, right middle temporal and posterior cingulate in the juvenile violent offenders.

\section{Discussion}

This study revealed altered resting-state DMN in juvenile violent offenders using ICA methodology. Compared with the normal controls, the offender group showed increased functional connectivity in the posterior cingulate and decreased functional connectivity in the right middle temporal, left angular, right precuneus and right middle frontal cortex.

The results showed the juvenile violent offenders had altered functional connectivity in the right middle temporal and frontal cortex, which was in line with prior studies that uncovered dysfunctions of frontal and temporal regions in violent populations. Key regions, including the temporal cortex and frontal cortex, are structurally and functionally impaired in the population with antisocial behaviors (Rosell

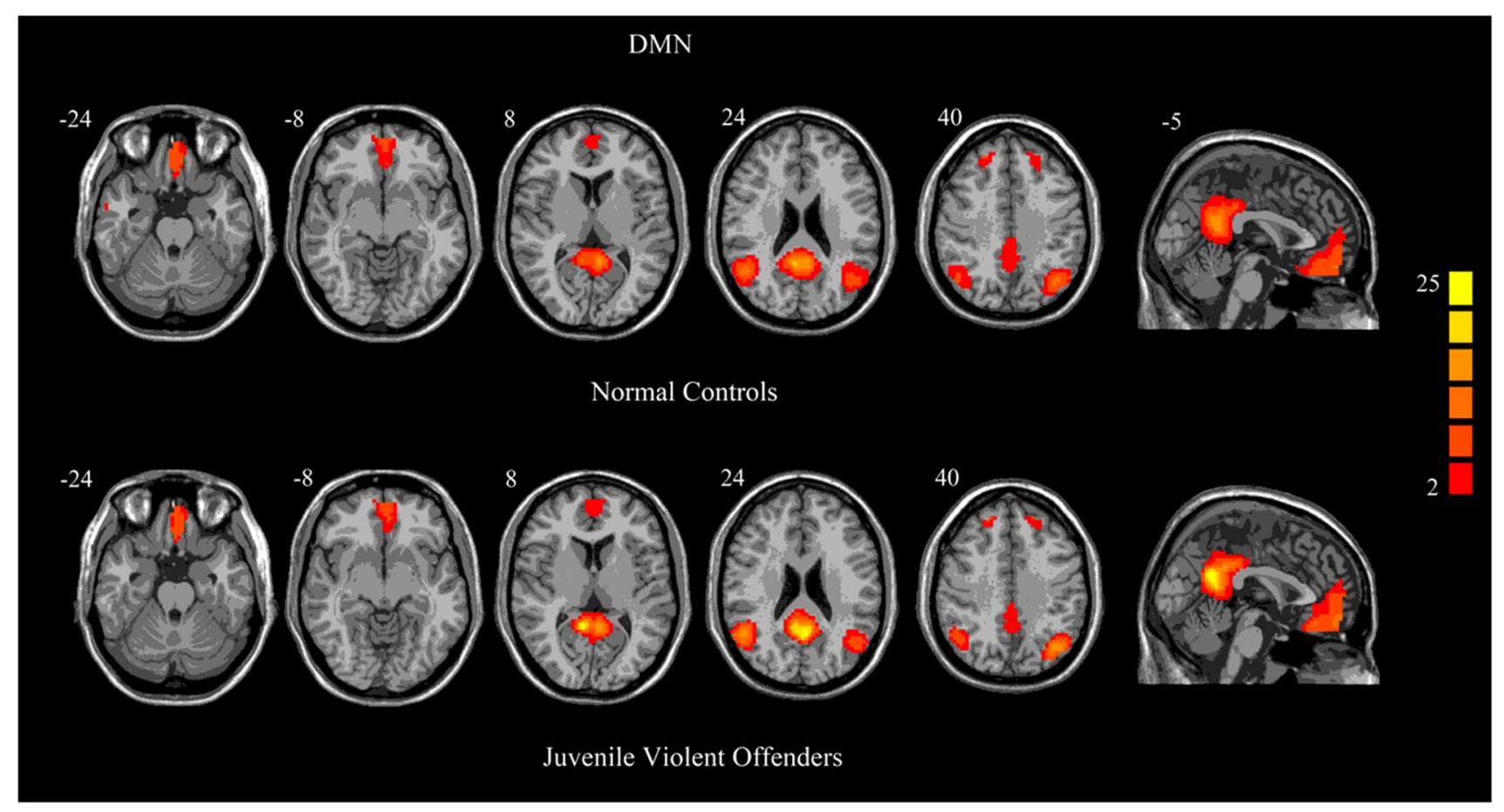

Fig. 1 One-sample t-test results for group-level DMN in normal controls and juvenile violent offenders. $p<0.05$, FDR corrected 
Fig. 2 Brain regions with significantly altered connectivity within DMN in juvenile violent offenders compared to normal controls. $p<0.05$ with AlphaSim correction

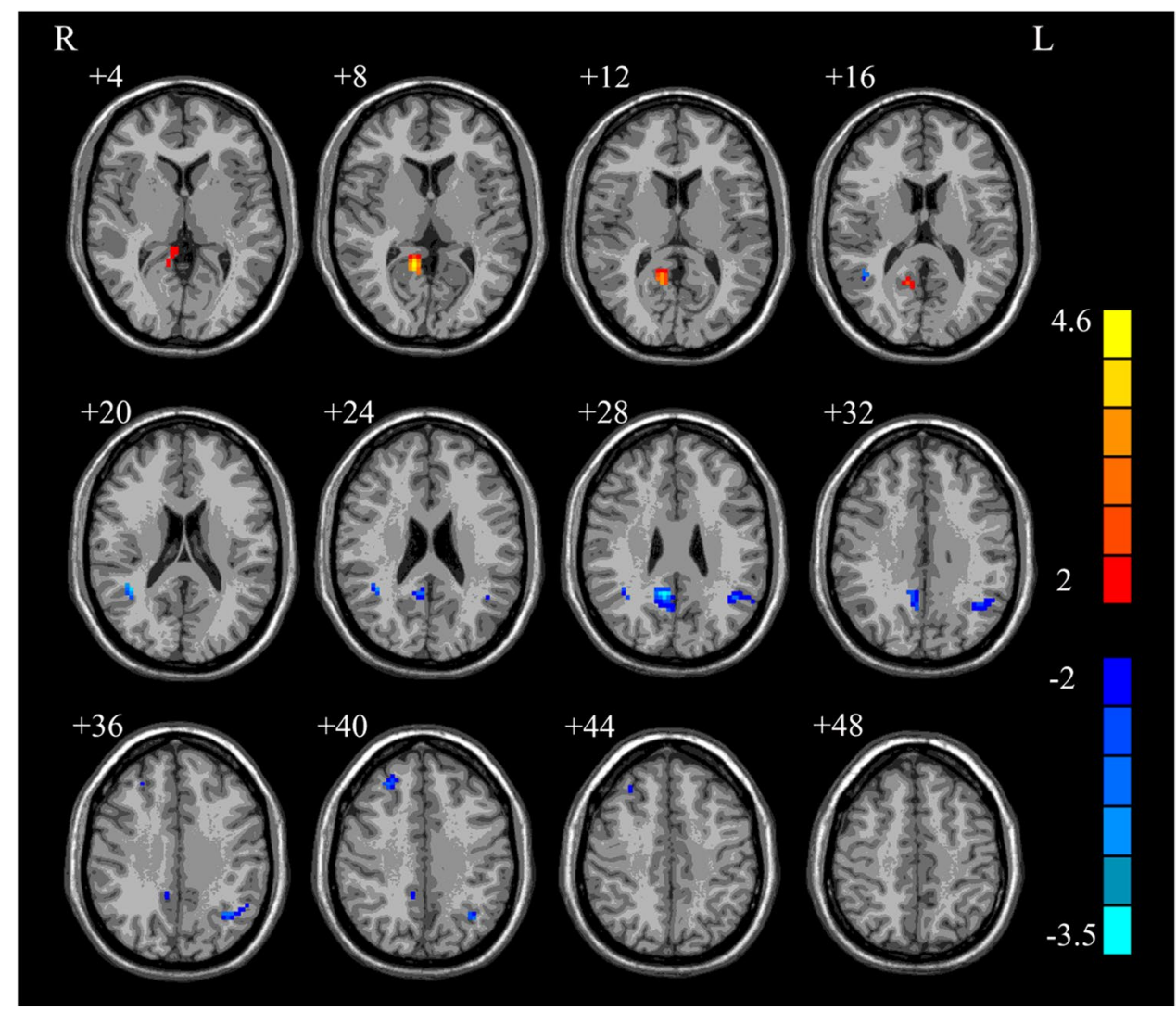

Table 3 Abnormal DMN regions in male juvenile violent offenders relative to normal controls. $p<0.05$ with AlphaSim correction

\begin{tabular}{llll}
\hline Region & $\frac{\text { Peak (MNI) }}{\mathrm{x} \quad \mathrm{y} \quad \mathrm{z}}$ & \\
& T value & \\
\end{tabular}

juvenile violent offenders $>$ normal controls

$\begin{array}{llllll}\text { Posterior cingulate } & 12 & -51 & 9 & 4.147 & 51\end{array}$

juvenile violent offenders $<$ normal controls

$\begin{array}{llllll}\text { Right middle temporal } & 39 & -48 & 21 & -3.048 & 23\end{array}$

Left angular $\quad-42 \quad-54 \quad 30 \quad-2.784 \quad 51$

$\begin{array}{llllll}\text { Right precuneus } & 9 & -51 & 30 & -3.451 & 63\end{array}$

Right middle frontal $\quad \begin{array}{lllll}27 & 36 & 39 & -2.506 & 20\end{array}$

\& Siever, 2015). Our previous study found that juvenile violent offenders showed significantly lower regional homogeneity values in the right medial prefrontal cortex than the controls (Chen et al., 2015). In addition, abnormalities of frontal cortex were also found in a group of patients with mental disorders who had a history of violence (Raichle et al., 2001; Shannon et al., 2011), as well as in some highrisk violent offenders (Fairchild et al., 2013; Pardini et al., 2014)

The right middle temporal and frontal area displayed lower functional connectivity in the juvenile violent offenders. One possible reason is that there are potential neurobiological differences in the DMN. Recent neurobiological studies support the idea that abnormalities in emotion-related brain areas may allow individuals to engage in aggressive acts (Yang et al., 2005). Previous studies have shown that the activation of fronto-temporal structures was related to the control over emotion-related behaviors and self-regulation. Patients with impulsive aggressive personality disorder were also found to have impaired emotion regulation and blunted prefrontal area (Leutgeb et al., 2015). Besides, functional abnormalities of certain regions of the frontal area, especially the orbitofrontal region, were related to poor inhibitory control, which might be the reason for excessive violent responses (Klasen et al., 2018). The frontal and temporal lobe play an essential role in regulating emotional and social behaviors (Kuroki et al., 2017), and are important for understanding the emotional of others (Yang et al., 2008), integrating moral knowledge with emotional cues (Schug \& Raine, 2009) and inhibiting aggressive impulses (Raine et al., 1997). Individuals with damages in these regions showed inadequate control of emotions as well as poor awareness of their own unsatisfying decision making (Lindberg et al., 2005). In this study, the offender group was associated with higher rate of inappropriate behaviors (such as smoking, drug and alcohol misuse) and higher detection rate of conduct disorder, which was consistent with the above viewpoints. In psychopathy, integrated 
functioning of the medial orbitofrontal cortex and amygdala in decision-making and stimulus-reinforcement learning is disrupted, which was considered to be the basis of the deficits in appropriate decision-making and socialization (Glenn $\&$ Raine, 2009). Aa a supplement for prior works, our study has revealed the association between violence and the disruption in fronto-temporal activity.

The posterior cingulate, precuneus and angular are key DMN hubs. A study found that the posterior cingulate was highly connected with many cortical and subcortical regions, such as medial temporal structures and the medial prefrontal cortex (New et al., 2002). In addition to structural studies that emphasized the important role of the posterior cingulate in brain organization, analyses on glucose metabolism showed that the posterior cingulate has a very high metabolic rate (Izquierdo, 2005; Rudebeck et al., 2008). The blood flow of the posterior cingulate and adjacent precuneus was $40 \%$ more than the average quantity (Vollm et al., 2006). The posterior cingulate, with such a hub-like organization, is particularly important for arousal and attention, and controls the balance between internally and externally focused thoughts (Moll et al., 2002). The high connectivity of posterior cingulate may indicate an increased level of arousal and attention on external events, which might explain the lower attentional impulsiveness in the present study. The current work showed lower connectivity in the right precuneus and left angular. In our previous study, lower regional homogeneity values in precuneus were found in violent offenders, compared with the controls (Brower \& Price, 2001). A coordinate-based meta-analysis showed altered activation in the right precuneus in aggressive individuals, compared with non-aggressive individuals, under different fMRI paradigms. This abnormality may further disrupt DMN and other neural networks, resulting in failure to generate adaptive responses when needed (Bechara, 2004). In male veterans with traumatic brain injuries, decreased functional connectivity between the angular region and the orbitofrontal cortex was associated with higher physical aggression score (Blair, 2007). The angular gyrus is considered to be one of the component of the brain network regarding moral reasoning (Hagmann et al., 2008), and is also essential in linking emotional experiences to moral appraisals (Raichle et al., 2001). These results suggest that the altered connectivity of the posterior cingulate, precuneus and angular regions might make male teenagers more prone to violence, and also highlighted that the aberrant DMN connectivity might represent a potential trait characteristic for juvenile violence.

In developing children, a correlation between impulsivity and functional connectivity in posterior DMN clusters was found (Inuggi et al., 2014). And the balance between the default network and attention and control networks may affect the impulsivity of individuals (Shannon et al., 2011). However, we did not find any correlation between the BIS-11 total score or scores of three factors and the connectivity in the right middle frontal, right precuneus, left angular, right middle temporal and posterior cingulate of DMN in the juvenile violent offenders. This may be due to the different tools used to measure impulsivity or that DMN clusters closely related impulsivity are not the above-mentioned.

There are several limitations in this study. Firstly, juvenile violent offenders had a shorter period of education, and they were one year older than the controls, which might affect our interpretation as well as the generalizability of the findings. At the stage of research design, we set a narrow age range of 15 to 18 years; but unfortunately, the age of the two groups did not match well. However, previous studies showed that the DMN matures into an "adult-like" network by the age of two (Gao et al., 2011; Keunen et al., 2017). It can be reliably identified in children and adolescents through long-term repeated measures with an interval of 2.5 years (Thomason et al., 2011). Therefore, by adolescence, the spatially distributed and functionally linked DMN has almost reached its adult state. Secondly, only males were included in this study in order to avoid the influence of sex on DMN activation patterns, which precluded us from obtaining relevant findings in females. In addition, it should be considered that aggression is a very heterogeneous construct (Vogt \& Laureys, 2005), which might be an important source of variability in brain activation among offenders. However, offenders in this study had committed crimes like armed robbery, assault, murder, or even a combination of those. This may limit the value of the results.

In conclusion, compared with the normal controls, the male juvenile violent offenders showed a different DMN pattern, including increased functional connectivity in the posterior cingulate and decreased functional connectivity in the right middle temporal, left angular, right precuneus and right middle frontal cortex. Abnormalities in these regions may lead to dysfunctions in regulating aggressive behaviors, such as inhibitory control deficits in emotional contexts. Therefore, we proposed that abnormal DMN in the resting-state might contribute to aggressive behaviors in juvenile violent offenders.

Funding This work was supported by the Fundamental Research Funds for the Central Universities of Central South University, National Natural Science Foundation of China (81571341, 81571316), Science and Technology Program of Hunan Province (2018SK2133) and Hunan Innovative Province Construction Project (2019SK2334).

\section{Declarations}

Conflict of interest The authors claim that there are no conflicts of interest. 
Ethics approval The study was approved by the Biomedical Ethics Board of the Second Xiangya Hospital of Central South University in China.

Consent to participate All the subjects and their legal guardians were fully informed of the procedures and signed the written informed consent form.

Open Access This article is licensed under a Creative Commons Attribution 4.0 International License, which permits use, sharing, adaptation, distribution and reproduction in any medium or format, as long as you give appropriate credit to the original author(s) and the source, provide a link to the Creative Commons licence, and indicate if changes were made. The images or other third party material in this article are included in the article's Creative Commons licence, unless indicated otherwise in a credit line to the material. If material is not included in the article's Creative Commons licence and your intended use is not permitted by statutory regulation or exceeds the permitted use, you will need to obtain permission directly from the copyright holder. To view a copy of this licence, visit http://creativecommons.org/licenses/by/4.0/.

\section{References}

Bechara, A. (2004). The role of emotion in decision-making: Evidence from neurological patients with orbitofrontal damage. Brain and Cognition, 55(1), 30-40. https://doi.org/10.1016/j.bandc.2003. 04.001

Blair, R. J. (2007). Dysfunctions of medial and lateral orbitofrontal cortex in psychopathy. Annals of the New York Academy of Sciences, 1121(1), 461-479. https://doi.org/10.1196/annals.1401.017

Boly, M., Balteau, E., Schnakers, C., Degueldre, C., Moonen, G., Luxen, A., ... Laureys, S. (2007). Baseline brain activity fluctuations predict somatosensory perception in humans. Proceedings of the National Academy of Sciences of the United States of America, 104(29), 12187-12192. https://doi.org/10.1073/pnas.0611404104

Brower, M. C., \& Price, B. H. (2001). Neuropsychiatry of frontal lobe dysfunction in violent and criminal behaviour: A critical review. Journal of Neurology, Neurosurgery and Psychiatry, 71(6), 720 726. https://doi.org/10.1136/jnnp.71.6.720

Buckner, R. L., Andrews-Hanna, J. R., \& Schacter, D. L. (2008). The brain's default network: Anatomy, function, and relevance to disease. Annals of the New York Academy of Sciences, 1124, 1-38. https://doi.org/10.1196/annals.1440.011

Chen, C., Zhou, J., Liu, C., Witt, K., Zhang, Y., Jing, B., ... Li, L. (2015). Regional homogeneity of resting-state brain abnormalities in violent juvenile offenders: a biomarker of brain immaturity? Journal of Neuropsychiatry and Clinical Neurosciences, 27(1), 27-32. https://doi.org/10.1176/appi.neuropsych.13030044

Czabański, J. (2008). Estimates of cost of crime. Springer, Berlin, Heidelberg. https://doi.org/10.1007/978-3-540-69805-0

Deco, G., Jirsa, V. K., \& McIntosh, A. R. (2011). Emerging concepts for the dynamical organization of resting-state activity in the brain. Nature Reviews Neuroscience, 12(1), 43-56. https://doi. org/10.1038/nrn2961

Fairchild, G., Hagan, C. C., Walsh, N. D., Passamonti, L., Calder, A. J., \& Goodyer, I. M. (2013). Brain structure abnormalities in adolescent girls with conduct disorder. Journal of Child Psychology and Psychiatry, 54(1), 86-95. https://doi.org/10.1111/j.1469-7610. 2012.02617.x

Farrington, D. P. (2003). Key Results from the First Forty Years of the Cambridge Study in Delinquent Development Taking Stock of Delinquency: An Overview of Findings from Contemporary
Longitudinal Studies (pp. 137-183). Springer US. https://doi.org/ 10.1007/0-306-47945-1_5

Fox, M. D., \& Raichle, M. E. (2007). Spontaneous fluctuations in brain activity observed with functional magnetic resonance imaging. Nature Reviews Neuroscience, 8(9), 700-711. https://doi.org/10. 1038/nrn2201

Gao, W., Gilmore, J. H., Giovanello, K. S., Smith, J. K., Shen, D., Zhu, H., \& Lin, W. (2011). Temporal and spatial evolution of brain network topology during the first two years of life. PLOS ONE, 6(9), e25278. https://doi.org/10.1371/journal.pone.0025278

Glenn, A. L., \& Raine, A. (2009). Psychopathy and instrumental aggression: Evolutionary, neurobiological, and legal perspectives. International Journal of Law and Psychiatry, 32(4), 253-258. https://doi.org/10.1016/j.ijlp.2009.04.002

Hagmann, P., Cammoun, L., Gigandet, X., Meuli, R., Honey, C. J., Wedeen, V. J., \& Sporns, O. (2008). Mapping the structural core of human cerebral cortex. PLoS Biology, 6(7), e159. https://doi. org/10.1371/journal.pbio.0060159

He, B. J. (2014). Scale-free brain activity: Past, present, and future. Trends in Cognitive Sciences, 18(9), 480-487. https://doi.org/ 10.1016/j.tics.2014.04.003

Immordino-Yang, M. H., Christodoulou, J. A., \& Singh, V. (2012). Rest Is Not Idleness. Perspectives on Psychological Science, 7(4), 352-364. https://doi.org/10.1177/1745691612447308

Inuggi, A., Sanz-Arigita, E., Gonzalez-Salinas, C., Valero-Garcia, A. V., Garcia-Santos, J. M., \& Fuentes, L. J. (2014). Brain functional connectivity changes in children that differ in impulsivity temperamental trait. Frontiers in Behavioral Neuroscience, 8, 156. https://doi.org/10.3389/fnbeh.2014.00156

Izquierdo, A. (2005). Comparison of the Effects of Bilateral Orbital Prefrontal Cortex Lesions and Amygdala Lesions on Emotional Responses in Rhesus Monkeys. Journal of Neuroscience, 25(37), 8534-8542. https://doi.org/10.1523/jneurosci.1232-05. 2005

Jacobs, H. I., Radua, J., Luckmann, H. C., \& Sack, A. T. (2013). Metaanalysis of functional network alterations in Alzheimer's disease: Toward a network biomarker. Neuroscience and Biobehavioral Reviews, 37(5), 753-765. https://doi.org/10.1016/j.neubiorev. 2013.03.009

Keunen, K., Counsell, S. J., \& Benders, M. (2017). The emergence of functional architecture during early brain development. NeuroImage, 160, 2-14. https://doi.org/10.1016/j.neuroimage.2017.01.047

Klasen, M., Wolf, D., Eisner, P. D., Habel, U., Repple, J., Vernaleken, I., ... Mathiak, K. (2018). Neural networks underlying trait aggression depend on MAOA gene alleles. Brain Structure and Function, 223(2), 873-881. https://doi.org/10.1007/s00429-017-1528-6

Krug, E. G., Mercy, J. A., Dahlberg, L. L., \& Zwi, A. B. (2002). The world report on violence and health. Lancet, 360(9339), 10831088. https://doi.org/10.1016/s0140-6736(02)11133-0

Kuroki, N., Kashiwagi, H., Ota, M., Ishikawa, M., Kunugi, H., Sato, N., ... Ota, T. (2017). Brain structure differences among male schizophrenic patients with history of serious violent acts: an MRI voxel-based morphometric study. BMC Psychiatry, 17(1), 105. https://doi.org/10.1186/s12888-017-1263-9

Laird, A. R., Eickhoff, S. B., Li, K., Robin, D. A., Glahn, D. C., \& Fox, P. T. (2009). Investigating the functional heterogeneity of the default mode network using coordinate-based meta-analytic modeling. Journal of Neuroscience, 29(46), 14496-14505. https:// doi.org/10.1523/JNEUROSCI.4004-09.2009

Leutgeb, V., Leitner, M., Wabnegger, A., Klug, D., Scharmuller, W., Zussner, T., \& Schienle, A. (2015). Brain abnormalities in highrisk violent offenders and their association with psychopathic traits and criminal recidivism. Neuroscience, 308, 194-201. https://doi.org/10.1016/j.neuroscience.2015.09.011

Lindberg, N., Tani, P., Virkkunen, M., Porkka-Heiskanen, T., Appelberg, B., Naukkarinen, H., \& Salmi, T. (2005). Quantitative 
electroencephalographic measures in homicidal men with antisocial personality disorder. Psychiatry Research, 136(1), 7-15. https://doi.org/10.1016/j.psychres.2005.05.005

Luo, C., Li, Q., Lai, Y., Xia, Y., Qin, Y., Liao, W., ... Gong, Q. (2011). Altered functional connectivity in default mode network in absence epilepsy: a resting-state fMRI study. Human Brain Mapping, 32(3), 438-449. https://doi.org/10.1002/hbm.21034

McDougall, P., \& Vaillancourt, T. (2015). Long-term adult outcomes of peer victimization in childhood and adolescence: Pathways to adjustment and maladjustment. American Psychologist, 70(4), 300-310. https://doi.org/10.1037/a0039174

Mckinlay, A., Corrigan, J., Horwood, L. J., \& Fergusson, D. M. (2013). Substance Abuse and Criminal Activities Following Traumatic Brain Injury in Childhood, Adolescence, and Early Adulthood. Journal of Head Trauma Rehabilitation, 29(6), 498. https://doi. org/10.1097/HTR.0000000000000001

Meehan, T. P., \& Bressler, S. L. (2012). Neurocognitive networks: Findings, models, and theory. Neuroscience and Biobehavioral Reviews, 36(10), 2232-2247. https://doi.org/10.1016/j.neubiorev. 2012.08.002

Mikton, C. R., Butchart, A., Dahlberg, L. L., \& Krug, E. G. (2016). Global Status Report on Violence Prevention 2014. American Journal of Preventive Medicine, 50(5), 652-659. https://doi.org/ 10.1016/j.amepre.2015.10.007

Moll, J., de Oliveira-Souza, R., Bramati, I. E., \& Grafman, J. (2002). Functional networks in emotional moral and nonmoral social judgments. NeuroImage, 16(3 Pt 1), 696-703. https://doi.org/10. 1006/nimg.2002.1118

New, A. S., Hazlett, E. A., Buchsbaum, M. S., Goodman, M., Reynolds, D., Mitropoulou, V., ... Siever, L. J. (2002). Blunted prefrontal cortical 18 fluorodeoxyglucose positron emission tomography response to meta-chlorophenylpiperazine in impulsive aggression. Archives of General Psychiatry, 59(7), 621-629. https://doi.org/ 10.1001/archpsyc.59.7.621

Pardini, D. A., Raine, A., Erickson, K., \& Loeber, R. (2014). Lower amygdala volume in men is associated with childhood aggression, early psychopathic traits, and future violence. Biological Psychiatry, 75(1), 73-80. https://doi.org/10.1016/j.biopsych.2013.04.003

Patton, J. H., Stanford, M. S., \& Barratt, E. S. (1995). Factor structure of the Barratt impulsiveness scale. Journal of Clinical Psychology, 51(6), 768-774. https://doi.org/10.1002/1097-4679(199511) 51:6\%3c768::aid-jclp2270510607\%3e3.0.co;2-1

Pessoa, L. (2008). On the relationship between emotion and cognition. Nature Reviews Neuroscience, 9(2), 148-158. https://doi.org/10. 1038/nrn2317

Piquero, A. R., Farrington, D. P., \& Blumstein, A. (2003). The Criminal Career Paradigm. Crime and Justice, 30, 359-506. https://doi. org/10.1086/652234

Raichle, M. E., MacLeod, A. M., Snyder, A. Z., Powers, W. J., Gusnard, D. A., \& Shulman, G. L. (2001). A default mode of brain function. Proc Natl Acad Sci U S A, 98(2), 676-682. https://doi. org/10.1073/pnas.98.2.676

Raine, A., Buchsbaum, M., \& Lacasse, L. (1997). Brain abnormalities in murderers indicated by positron emission tomography. Biological Psychiatry, 42(6), 495-508. https://doi.org/10.1016/ s0006-3223(96)00362-9

Rosell, D. R., \& Siever, L. J. (2015). The neurobiology of aggression and violence. CNS Spectrums, 20(3), 254-279. https://doi.org/10. 1017/S109285291500019X
Rudebeck, P. H., Bannerman, D. M., \& Rushworth, M. F. (2008). The contribution of distinct subregions of the ventromedial frontal cortex to emotion, social behavior, and decision making. Cognitive, Affective, \& Behavioral Neuroscience, 8(4), 485-497. https:// doi.org/10.3758/CABN.8.4.485

Schug, R. A., \& Raine, A. (2009). Comparative meta-analyses of neuropsychological functioning in antisocial schizophrenic persons. Clinical Psychology Review, 29(3), 230-242. https://doi.org/10. 1016/j.cpr.2009.01.004

Shannon, B. J., Raichle, M. E., Snyder, A. Z., Fair, D. A., Mills, K. L., Zhang, D., ... Kiehl, K. A. (2011). Premotor functional connectivity predicts impulsivity in juvenile offenders. Proceedings of the National Academy of Sciences of the United States of America, 108(27), 11241-11245. https://doi.org/10.1073/pnas.1108241108

Stanford, M. S., Mathias, C. W., Dougherty, D. M., Lake, S. L., Anderson, N. E., \& Patton, J. H. (2009). Fifty years of the Barratt Impulsiveness Scale: An update and review. Personality and Individual Differences, 47(5), 385-395. https://doi.org/10.1016/j.paid.2009. 04.008

Thomason, M. E., Dennis, E. L., Joshi, A. A., Joshi, S. H., Dinov, I. D., Chang, C., ... Gotlib, I. H. (2011). Resting-state fMRI can reliably map neural networks in children. Neuroimage, 55(1), 165-175. https://doi.org/10.1016/j.neuroimage.2010.11.080

Vogt, B. A., \& Laureys, S. (2005). Posterior cingulate, precuneal and retrosplenial cortices: Cytology and components of the neural network correlates of consciousness. Progress in Brain Research, 150, 205-217. https://doi.org/10.1016/S0079-6123(05)50015-3

Vollm, B. A., Taylor, A. N., Richardson, P., Corcoran, R., Stirling, J., McKie, S., ... Elliott, R. (2006). Neuronal correlates of theory of mind and empathy: a functional magnetic resonance imaging study in a nonverbal task. Neuroimage, 29(1), 90-98. https://doi. org/10.1016/j.neuroimage.2005.07.022

Wahlund, K., \& Kristiansson, M. (2009). Aggression, psychopathy and brain imaging - Review and future recommendations. International Journal of Law and Psychiatry, 32(4), 266-271. https:// doi.org/10.1016/j.ijlp.2009.04.007

Welsh, B. C., Loeber, R., Stevens, B. R., Stouthamer-Loeber, M., Cohen, M. A., \& Farrington, D. P. (2008). Costs of Juvenile Crime in Urban Areas. Youth Violence and Juvenile Justice, 6(1), 3-27. https://doi.org/10.1177/1541204007308427

Yang, Y., Glenn, A. L., \& Raine, A. (2008). Brain abnormalities in antisocial individuals: Implications for the law. Behavioral Sciences \& the Law, 26(1), 65-83. https://doi.org/10.1002/bsl.788

Yang, Y., Raine, A., Lencz, T., Bihrle, S., LaCasse, L., \& Colletti, P. (2005). Volume reduction in prefrontal gray matter in unsuccessful criminal psychopaths. Biological Psychiatry, 57(10), 11031108. https://doi.org/10.1016/j.biopsych.2005.01.021

Zhou, J., Chen, C., Wang, X., Cai, W., Zhang, S., Qiu, C., ... Fazel, S. (2012). Psychiatric disorders in adolescent boys in detention: a preliminary prevalence and case-control study in two Chinese provinces. Journal of Forensic Psychiatry \& Psychology, 23(5-6), 664-675. https://doi.org/10.1080/14789949.2012.727452

Publisher's Note Springer Nature remains neutral with regard to jurisdictional claims in published maps and institutional affiliations. 